\title{
Characterization of Phenotype and Genotype of Biofield Treated Enterobacter aerogenes
}

\author{
Mahendra Kumar Trivedi ${ }^{1}$, Alice Branton ${ }^{1}$, Dahryn Trivedi ${ }^{1}$, Gopal Nayak ${ }^{1}$, Mayank Gangwar ${ }^{2}$ and Snehasis Jana ${ }^{*}$ \\ ${ }^{1}$ Trivedi Global Inc., 10624 S Eastern Avenue Suite A-969, Henderson, NV 89052, USA \\ ${ }^{2}$ Trivedi Science Research Laboratory Pvt. Ltd., Hall-A, Chinar Mega Mall, Chinar Fortune City, Hoshangabad Rd, Bhopal-462026, Madhya Pradesh, India
}

\begin{abstract}
Enterobacter aerogenes ( $E$. aerogenes) has been commonly described as a versatile opportunistic pathogen in hospital infections. The aim of the present work was to evaluate the impact of biofield treatment on $E$. aerogenes for its phenotypic and genotypic characteristics. E. aerogenes bearing ATCC 13048 (American Type Culture Collection) was procured from Bangalore Genei, in sealed pack and divided into control and treated groups. Treated group was subjected to Mr. Trivedi's biofield treatment and analyzed for antimicrobial susceptibility, minimum inhibitory concentration (MIC), biochemical reactions, and biotype using automated MicroScan Walk-Away ${ }^{\circledR}$ system. In addition, treated group of $E$. aerogenes was evaluated for DNA polymorphism by Random Amplified Polymorphic DNA (RAPD) and $16 \mathrm{~S}$ rDNA sequencing to establish the phylogenetic relationship of $E$. aerogenes with different closely related bacterial species. Antimicrobial susceptibility results showed an alteration of $14.28 \%$ among twenty-eight tested antimicrobials. Similarly, $15.65 \%$ tested antimicrobials showed an alteration in MIC values. Chloramphenicol showed improved sensitivity i.e. resistant to susceptible after biofield treatment, with the support of decreased MIC by two folds (i.e. $>16$ to $\leq 8 \mu \mathrm{g} / \mathrm{mL}$ ). Norfloxacin also showed decrease MIC by two folds (i.e. 8 to $\leq 4 \mu \mathrm{g} / \mathrm{mL}$ ) as compared to control. Biofield treatment showed an impact on biochemical reactions $(9.09 \%)$ followed by a change in biotype number (7770 5272) in treated group with respect to control (7770 5372). Using RAPD analysis, sample showed an average range of 4 to $42 \%$ of polymorphism, while $16 \mathrm{~S}$ rDNA study showed that treated sample was detected as Kluyvera cryocrescens (GenBank Accession Number: AM184245) with $97 \%$ identity of gene sequencing data, which was nearest homolog species to Enterobacter aerogenes strain: C1111 (Accession No. AB244467). These results suggest that Mr. Trivedi's unique biofield treatment can alter the antimicrobial sensitivity pattern, thus it can be used as alternate energy medicine in future.
\end{abstract}

Keywords: Enterobacter aerogenes, Biofield treatment; Phenotyping, Polymorphism; RAPD; 16S rDNA analysis

\section{Introduction}

Enterobacter aerogenes (E. aerogenes) is a common organism of most of the hospital-acquired infections. Adaptive capability of $E$. aerogenes is remarkable and can easily acquire resistance to against $\beta$-lactam antibiotics [1]. During last five years, it has shown that $E$. aerogenes isolates are having natural resistance against aminopenicillins, and express an extended-spectrum $\beta$-lactamase (ESBL), which results resistance to $\beta$-lactam antibiotics [2]. However, E. aerogenes exhibits acquired resistance against different categories of antimicrobial agents. General resistance mechanisms exhibited by E. aerogenes involves membrane permeability, p-glycoprotein efflux pump, and enzyme degradation against carbapenems, fluoroquinolones, quinolones, tetracycline, and chloramphenicol [3]. Currently, colistin, and polymyxin antibiotic have been preferred as alternative drugs against Gram-negative pathogens, due to the extended resistance of Gramnegative bacteria against almost all antibiotics [4]. Recently, colistin in antibiotic therapy shows serious toxicity and associated adverse effects like neurotoxicity and nephrotoxicity [5]. Because of all the associated side effects and failure of drug treatment therapy, alternate treatment approach is required. Recently, an alternate treatment is known as biofield energy and is reported that inhibits the growth of bacterial cultures [6].

Biofield is the name given to the electromagnetic field that permeates and surrounds living organisms [7]. It is referred as biologically produced electromagnetic and subtle energy field that provides regulatory and communication functions within the human organism. Various internal physiological processes such as blood flow, brain, heart function, etc. that generate biofield. Biomagnetic fields around the human body can be measured using different techniques [8]. Researchers have attempted different biological studies and effects of biofield on various biomolecules such as proteins, antibiotics [9], and conformational change in DNA [10], bacterial cultures [11] etc. Thus, it can be concluded that human can to harness the energy from environment or universe and can transmit into any living or nonliving object(s) around the Universe. The objects always receive the energy and responding to useful way that is called biofield energy. Mr. Trivedi's unique biofield treatment has been well known and studied in the field of material science [12-14], agricultural science [15-17], and biotechnology [18]. Mr. Trivedi's unique biofield treatment is also known as The Trivedi Effect ${ }^{\circ}$, which was also reported in altering the susceptibility of antimicrobials against pathogenic and multidrug resistant microbes [19-21].

After consideration of the clinical significance of E. aerogenes and significant impact of Mr. Trivedi's biofield treatment on microbes, authors evaluated the effect of biofield treatment on E. aerogenes followed by genotyping of treated organism. Genotyping was performed using strain differentiation and distinctive polymorphism using polymerase chain reaction (PCR) technique of random amplified polymorphic DNA analysis (RAPD) and $16 \mathrm{~S}$ rDNA sequencing.

\section{Materials and Methods}

*Corresponding author: Jana S, Trivedi Science Research Laboratory Pvt. Ltd. Hall-A, Chinar Mega Mall, Chinar Fortune City, Hoshangabad Rd, Bhopal-462026, Madhya Pradesh, India, Tel: +91-755-6660006; E-mail: publication@trivedisrl.com

Received August 15, 2015; Accepted September 02, 2015; Published September 12, 2015

Citation:Trivedi MK, Branton A, Trivedi D, Nayak G, Gangwar M, et al. (2015) Characterization of Phenotype and Genotype of Biofield Treated Enterobacter aerogenes. Transl Med 5: 155. doi:10.4172/2161-1025.1000155

Copyright: (c 2015 Trivedi MK, et al., This is an open-access article distributed under the terms of the Creative Commons Attribution License, which permits unrestricted use, distribution, and reproduction in any medium, provided the original author and source are credited. 
Enterobacter aerogenes ATCC 13048 [American Type Culture Collection] was procured from Bangalore Genei, in sealed pack, and stored as per the recommended storage conditions for further use. The anti-microbial susceptibility, biochemical reactions, and biotype number were evaluated on MicroScan Walk-Away ${ }^{\oplus}$ (Dade Behring Inc., West Sacramento, CA) using Negative Breakpoint Combo 30 (NBPC 30) panel. DNA fingerprinting (RAPD) and the $16 \mathrm{~S}$ rDNA sequencing studies were carried out using Ultrapure Genomic DNA Prep Kit; Cat KT 83 (Bangalore Genei, India). All the tested antimicrobials, biochemicals and other reagents were procured from Sigma-Aldrich, India.

\section{Study design and biofield treatment}

E. aerogenes strain was divided into two groups i.e. control and treatment. The treatment group was in sealed pack and handed over to Mr. Trivedi for biofield treatment under laboratory conditions. Mr. Trivedi provided the treatment through his energy transmission process to the treated group without touching the sample. After treatment, control and treated groups were assessed on day 10 for antimicrobial susceptibility, minimum inhibitory concentration (MIC), biochemical reactions, biotype, and genotyping using RAPD and 16S rDNA analysis. The results of treated samples were compared with respect to control.

\section{Investigation of antimicrobial susceptibility assay}

Investigation of antimicrobial susceptibility of E. aerogenes was carried out with the help of automated instrument, MicroScan WalkAway ${ }^{\oplus}$ using Negative Breakpoint Combo 30 (NBPC30) panel as per the manufacturer's instructions. The panel was allowed to equilibrate to room temperature prior to rehydration. All opened panel were used on the same day. The tests were carried out on MicroScan, which were miniaturized of the broth dilution susceptibility test that has been dehydrated. Briefly, $0.1 \mathrm{~mL}(100 \mu \mathrm{L})$ of the standardized suspension of E. aerogenes was pipetted into $25 \mathrm{~mL}$ of inoculum water using pluronic and inverted 8-10 times and inoculated, rehydrated, and then subjected to incubation for 16 hours at $35^{\circ} \mathrm{C}$. Rehydration and inoculation was performed using the RENOK ${ }^{\circ}$ system with inoculators-D (B1013-4). The detailed experimental procedures and conditions were followed as per the manufacturer's instructions. Briefly, after inoculation and rehydration with a standardized suspension of $E$. aerogenes, it was incubated at $35^{\circ} \mathrm{C}$ for 16 hours. MIC and a qualitative susceptibility like susceptible (S), intermediate (I), inducible $\beta$-lactamases (IB), and resistant $(\mathrm{R})$ were determined by observing the lowest antimicrobial concentration showing growth inhibition [22].

Biochemical studies: The biochemical reactions of $E$. aerogenes were determined by MicroScan Walk-Away ${ }^{\oplus}$ system, it interprets the microbe biochemical results with the use of a photometric or fluorogenic reader. On the basis of nature of bacilli (Gram-negative or Gram-positive), it generates computerized reports using conventional panels, which utilizes the photometric reader and provide identification results. Before commencing the experiment, the NBPC 30 panel was first incubated and read on the MicroScan Walkaway system. After completion of reading on the Walkaway system, the NBPC 30 panel was removed from system and read on the Biomic system within 1 hour. MicroScan Walk-Away instrument consist of a database associated with collective information, which was required to identify the group, genera, or species of the family. Detailed experimental procedure was followed as per manufacturer-recommended instructions [22].

Biotype number: The biotype number of $E$. aerogenes was determined by MicroScan Walk-Away processed panel data utilizing data of biochemical reactions. Similar experimental procedure was followed for identification of biotype number as described in biochemical reaction study, and as per manufacturer-recommended instructions [22].

\section{Random Amplified Polymorphic DNA (RAPD) analysis}

Three series of inoculums (one for control and other two for treatment named as treatment $\mathrm{A}$ and $\mathrm{B}$ ) were prepared from $E$. aerogenes sample. Two inoculums (treatment samples A and B) were subjected to Mr. Trivedi's biofield treatment. Whilst handing over treated groups to Mr. Trivedi for biofield treatment, optimum precautions were taken to avoid the contamination. After that, the treated samples (A and B) were sub-cultured by taking $1 \%$ inoculum and inoculated to fresh $5 \mathrm{~mL}$ medium and labeled as treatment A-1 and treatment B-1 respectively. Control and treated samples were incubated at $37^{\circ} \mathrm{C}$ with $160 \mathrm{rpm}$ for $18 \mathrm{~h}$. Subsequently, the cultures were spun down, and genomic DNA was isolated for control and treated samples using Genomic DNA Prep Kit (Bangalore Genei, India). Designed primers were initially screened for their sharpness, further primers that have the basic of sharpness, clarity of the profile and the existence of polymorphisms were chosen for further study. RAPD was performed with all samples of E. aerogenes using five RAPD primers, which were labelled as RBA8A, RBA13A, RBA20A, RBA10A and RBA15A. The PCR mixture contained $2.5 \mu \mathrm{L}$ each of buffer, $4.0 \mathrm{mM}$ each of dNTP, $2.5 \mu \mathrm{M}$ each of primer, $5.0 \mu \mathrm{L}$ each of genomic DNA, $2 \mathrm{U}$ each of Taq polymerase, $1.5 \mu \mathrm{L}$ of $\mathrm{MgCl}_{2}$ and 9.5 $\mu \mathrm{L}$ of nuclease-free water in a total of $25 \mu \mathrm{L}$ mixture. PCR amplification protocol followed with initial denaturation at $94^{\circ} \mathrm{C}$ for $7 \mathrm{~min}$, followed by 8 cycles of denaturation at $94^{\circ} \mathrm{C}$ for $1 \mathrm{~min}$, annealing at $35^{\circ} \mathrm{C}$ for 1 min, and extension at $72^{\circ} \mathrm{C}$ for $2 \mathrm{~min}$; and 35 cycle of denaturation at $94^{\circ} \mathrm{C}$ for $1 \mathrm{~min}$, annealing at $38^{\circ} \mathrm{C}$ for $1 \mathrm{~min}$, and extension at $72^{\circ} \mathrm{C}$ for $1.5 \mathrm{~min}$; and the final extension at $72^{\circ} \mathrm{C}$ for $7 \mathrm{~min}$. Amplified PCR products $(12 \mu \mathrm{L})$ from all samples (control and treated) were separated on $1.5 \%$ agarose gels at 75 volts, stained with ethidium bromide and visualized under UV illumination [23].

The percentage of polymorphism was calculated using following equation-

\section{Percent polymorphism $=\mathrm{A} / \mathrm{B} \times 100$;}

Where, $\mathrm{A}=$ number of polymorphic bands in treated sample; and $\mathrm{B}$ $=$ number of polymorphic bands in control.

\section{Amplification and gene sequencing of 16S rDNA}

Genomic DNA was isolated and purified from a treated group of $E$. aerogenes cells by using genomic purification Kit, as per the manufacturer's instructions. The PCR product was bi-directionally sequenced using the forward, reverse, and an internal primer. DNA $16 \mathrm{~S}$ region amplification was performed using the primer set $16 \mathrm{~S}$ forward and reverse primer [24]. 16S rDNA gene $(\sim 1.5 \mathrm{~kb})$ was amplified by universal primers; forward primer (5'-AGAGTTTGATCCTGGCTCAG-3') and reverse primer ( $3^{\prime}$-ACGGTCATACCTTGTTACGACTT-5'). Amplification was carried out in a Rapid Cycler thermocontroller, with initial denaturation, annealing and extension temperature. Following amplification products were analyzed by gel electrophoresis at $100 \mathrm{~V}$ (in $1.0 \%$ agarose gel, $0.2 \mu \mathrm{g}$ of ethidium bromide $\mathrm{mL}^{-1}$ ) in tris-acetate buffer (TAE), and visualized under UV light in a gel documentation unit (BioRad Laboratories, USA). The amplified fragment of PCR was purified from the agarose gel by DNA Gel Extraction Kit. Sequencing of amplified product was carried out on a commercial basis from Bangalore Genei, India. The obtained 16S rDNA sequences data were aligned and compared with the sequences, available in GenBank database of National Center for Biotechnology Information (NCBI) using the algorithm BLASTn program. The multiple sequence alignment/ 
Citation: Trivedi MK, Branton A, Trivedi D, Nayak G, Gangwar M, et al. (2015) Characterization of Phenotype and Genotype of Biofield Treated Enterobacter aerogenes. Transl Med 5: 155. doi:10.4172/2161-1025.1000155

Page 3 of 7

phylogenetic tree were constructed using MEGA 3.1 software using neighbor-joining method [25].

\section{Results and Discussion}

\section{Assessment of antimicrobial susceptibility}

The effect of biofield treatment on E. aerogenes with respect to antimicrobials susceptibility pattern and MIC are summarized in Tables 1 and 2 , respectively. The data were analyzed and compared with respect to control. The treated cells of E. aerogenes showed $14.28 \%$ alteration out of twenty-eight tested antimicrobials as compared to control. Results showed altered antibiogram of cefotaxime, cefotetan, chloramphenicol, and piperacillin as compared to control. Cefotaxime was converted from inducible $\beta$-lactamases to intermediate, while cefotetan changed from inducible $\beta$-lactamases to resistant. Chloramphenicol resistance profile was improved from resistant to susceptible as compared to control. Piperacillin sensitivity was also altered from inducible $\beta$-lactamases to intermediate. Rest of the tested antimicrobials did not show any alteration in sensitivity with respect to control.

Similarly, sensitivity results of tested antimicrobials are well supported with MIC results (Table 2). Cefotaxime showed four folds alteration in MIC value $(32 \mu \mathrm{g} / \mathrm{mL})$ while cefotetan showed two folds change in MIC value ( $>32 \mu \mathrm{g} / \mathrm{mL})$ with respect to control. Improved sensitivity of chloramphenicol also showed decreased MIC value by two folds (i.e. $>16$ to $\leq 8 \mu \mathrm{g} / \mathrm{mL}$ ) as compared to control. Norfloxacin also a showed decrease in MIC value by two folds after biofield treatment with

\begin{tabular}{|c|c|c|c|}
\hline S. No. & Antimicrobial & Control & Treated \\
\hline 1 & Amikacin & $\mathrm{s}$ & $\mathrm{s}$ \\
\hline 2 & Amoxicillin/k-clavulanate & $\mathrm{R}$ & $\mathrm{R}$ \\
\hline 3 & Ampicillin/sulbactam & 1 & 1 \\
\hline 4 & Ampicillin & $\mathrm{R}$ & $\mathrm{R}$ \\
\hline 5 & Aztreonam & IB & IB \\
\hline 6 & Cefazolin & $R$ & $\mathrm{R}$ \\
\hline 7 & Cefepime & S & $S$ \\
\hline 8 & Cefotaxime & IB & 1 \\
\hline 9 & Cefotetan & IB & $\mathrm{R}$ \\
\hline 10 & Cefoxitin & $\mathrm{R}$ & $R$ \\
\hline 11 & Ceftazidime & IB & IB \\
\hline 12 & Ceftriaxone & IB & IB \\
\hline 13 & Cefuroxime & IB & IB \\
\hline 14 & Cephalothin & $\mathrm{R}$ & $\mathrm{R}$ \\
\hline 15 & Chloramphenicol & $R$ & S \\
\hline 16 & Ciprofloxacin & S & $S$ \\
\hline 17 & Gatifloxacin & s & S \\
\hline 18 & Gentamicin & S & S \\
\hline 19 & Imipenem & S & $S$ \\
\hline 20 & Levofloxacin & s & S \\
\hline 21 & Meropenem & S & S \\
\hline 22 & Moxifloxacin & $S$ & $S$ \\
\hline 23 & Piperacillin/tazobactam & IB & IB \\
\hline 24 & Piperacillin & IB & 1 \\
\hline 25 & Tetracycline & $S$ & $S$ \\
\hline 26 & Ticarcillin/k-clavulanate & IB & IB \\
\hline 27 & Tobramycin & S & S \\
\hline 28 & Trimethoprim/sulfamethoxazole & $S$ & $S$ \\
\hline
\end{tabular}

R: Resistant; I: Intermediate; S: Susceptible; '-': IB: Inducible ß-lactamases; deleted Table 1: Effect of biofield treatment on multidrug resistant lab isolates of Enterobacter aerogenes to antimicrobial susceptibility.

\begin{tabular}{|c|c|c|c|}
\hline S. No. & Antimicrobial & Control & Treated \\
\hline 1 & Amikacin & $\leq 16$ & $\leq 16$ \\
\hline 2 & Amoxicillin/K-clavulanate & $>16 / 8$ & $>16 / 8$ \\
\hline 3 & Ampicillin/sulbactam & $16 / 8$ & $16 / 8$ \\
\hline 4 & Ampicillin & $>16$ & $>16$ \\
\hline 5 & Aztreonam & $\leq 8$ & $\leq 8$ \\
\hline 6 & Cefazolin & $>16$ & $>16$ \\
\hline 7 & Cefepime & $\leq 8$ & $\leq 8$ \\
\hline 8 & Cefotaxime & $\leq 8$ & 32 \\
\hline 9 & Cefotetan & $\leq 16$ & $>32$ \\
\hline 10 & Cefoxitin & $>16$ & $>16$ \\
\hline 11 & Ceftazidime & $\leq 8$ & $\leq 8$ \\
\hline 12 & Ceftriaxone & $\leq 8$ & $\leq 8$ \\
\hline 13 & Cefuroxime & $\leq 4$ & $\leq 4$ \\
\hline 14 & Cephalothin & $>16$ & $>16$ \\
\hline 15 & Chloramphenicol & $>16$ & $\leq 8$ \\
\hline 16 & Ciprofloxacin & $\leq 1$ & $\leq 1$ \\
\hline 17 & ESBL-a Scrn & $\leq 4$ & $\leq 4$ \\
\hline 18 & ESBL-b Scrn & $\leq 1$ & $\leq 1$ \\
\hline 19 & Gatifloxacin & $\leq 2$ & $\leq 2$ \\
\hline 20 & Gentamicin & $\leq 4$ & $\leq 4$ \\
\hline 21 & Imipenem & $\leq 4$ & $\leq 4$ \\
\hline 22 & Levofloxacin & $\leq 2$ & $\leq 2$ \\
\hline 23 & Meropenem & $\leq 4$ & $\leq 4$ \\
\hline 24 & Moxifloxacin & $\leq 2$ & $\leq 2$ \\
\hline 25 & Nitrofurantoin & 64 & 64 \\
\hline 26 & Norfloxacin & 8 & $\leq 4$ \\
\hline 27 & Piperacillin/tazobactam & $\leq 16$ & $\leq 16$ \\
\hline 28 & Piperacillin & $\leq 16$ & 64 \\
\hline 29 & Tetracycline & $\leq 4$ & $\leq 4$ \\
\hline 30 & Ticarcillin/k-clavulanate & $\leq 16$ & $\leq 16$ \\
\hline 31 & Tobramycin & $\leq 4$ & $\leq 4$ \\
\hline 32 & Trimethoprim/sulfamethoxazole & $\leq 2 / 38$ & $\leq 2 / 38$ \\
\hline
\end{tabular}

MIC values are presented in $\mu \mathrm{g} / \mathrm{mL}$; ESBL: Suspected extended-spectrum $\beta$-lactamases $a, b$ screen

Table 2: Minimum inhibitory concentration (MIC) of tested antimicrobials against Enterobacter aerogenes.

respect to control (i.e. 8 to $\leq 4 \mu \mathrm{g} / \mathrm{mL}$ ). However, piperacillin showed four folds change in MIC value (i.e. $\leq 16$ to $64 \mu \mathrm{g} / \mathrm{mL}$ ) as compared to control. Overall, $15.65 \%$ tested antimicrobials showed altered MIC values with respect to control. The rest of the tested antimicrobials did not show any alteration in MIC values with respect to control data.

According to National health statistics reports of National Center for Health Statistics in the Unites States, 2002-2012, biofield treatment as an alternative energy medicine was well reported and practiced among adults [26]. The current experiment was designed to demonstrate the impact of biofield treatment on E. aerogenes for its susceptibility pattern, biochemical reaction, and biotype number. Further, molecular methods were performed to study the genetic alterations and similarities using RAPD and 16S rDNA sequencing methods. Increased emergence of resistant E. aerogenes is a global health problem, as an emerging Gram-negative pathogen in Enterobacteriaceae family, associated with severe hospital acquired infections. E. aerogenes isolates have a broad ability to develop antimicrobial resistance [27]. Results showed, biofield treatment has induced change in susceptibility pattern of antimicrobials such as cefotaxime, cefotetan, chloramphenicol, and piperacillin as compared to control. Chloramphenicol showed improved sensitivity after biofield treatment from resistant to susceptible. Chloramphenicol exhibited natural resistance against $E$. aerogenes, and it was mediated 
either enzymatically through acetylation of the drug or mechanically via active drug efflux [28]. Moreover, general resistance mechanism involves in Enterobacter sp. against tetracycline, fluoroquinolones and chloramphenicol through efflux mechanism to expel the antimicrobials [3]. Biofield treatment on E. aerogenes showed improved susceptibility of chloramphenicol, which suggested that biofield treatment might acetylate the chloramphenicol molecule. Improved sensitivity might be correlated with acetylation that may happen via active drug efflux mechanism as compared to control.

A significant decreased MIC value of chloramphenicol with increased antimicrobial sensitivity was reported with respect to control. Increased incidence of nosocomial infections and broad resistance to third generation cephalosporins, penicillins and quinolones are a serious problem. However, fourth generation antimicrobials remain effective for treatment but with serious side effects [29]. Aminoglycosides, quinolones, trimethoprim/sulphamethoxazole, and carbapenems displayed good activity against Gram-negative pathogens including Enterobacter species [30]. Mr. Trivedi's biofield treatment showed a significant decrease in MIC values of chloramphenicol and norfloxacin, which suggested an alteration at enzymatic/genetic level. Alterations might affect the $\beta$-lactamases production that may lead to decrease the MIC, which is required to inhibit the growth of E. aerogenes.

\section{Organism identification by biochemical reactions}

The biochemical reactions of E. aerogenes are presented in Table 3. Overall, $9.09 \%$ biochemical reactions were altered out of thirtythree tested biochemicals. In the present study, nitrate and VogesProskauer biochemicals showed negative reaction i.e. positive $(+)$ to negative (-) as compared to control. However, kanamycin showed positive reaction i.e. negative (-) to positive (+) with compared to control. Rest of thirty biochemicals did not show any alteration in metabolic reactions with respect to control. Different phenotypic identification tests were available to differentiate the Enterobacter species. Experimental identification of E. aerogenes was performed using a series of biochemical reactions. Enterobacter species have basic characteristic reactions such as the presence of Voges-Proskauer, sucrose, dextrose, glucose, lactose, rhamnose, citrate, lysine, ornithine decarboxylase, and motile in nature. Indole, methyl red and hydrogen sulphide are the negative characteristic tests of Enterobacter species. Biochemical reactions tested in the control group were well supported with literature data [31,32]. Biofield treatment might involve some enzymatic alterations in E. aerogenes, which resulted in alterations in characteristic biochemical reactions.

\section{Organism identification by biotype number}

E. aerogenes was identified based on a variety of conventional biochemical characters and biotyping. After interpreting the results of the biochemical reactions, biotype number of E. aerogenes was evaluated using automated Microscan system. The biotype number then led to the organism identification. In this experiment, biotyping was performed, and results found a significant change in biotype number (7770 5272) in treated group as compared to control (7770 5372). Organism identified in both the groups was same as E. aerogenes. Our research group recently reported the significant alterations in biochemical reactions followed by the change in biotype number that also supported with published data [18-20].

\section{Random Amplified Polymorphic DNA (RAPD) analysis}

Treated and control samples were identified on the basis of their different and discriminative RAPD patterns. RAPD is a new tool that is

\begin{tabular}{|c|c|c|c|c|}
\hline S. No. & Code & Biochemical & Control & Treated \\
\hline 1 & ACE & Acetamide & - & - \\
\hline 2 & ADO & Adonitol & + & + \\
\hline 3 & ARA & Arabinose & + & + \\
\hline 4 & ARG & Arginine & - & - \\
\hline 5 & CET & Cetrimide & - & - \\
\hline 6 & CF8 & Cephalothin & + & + \\
\hline 7 & CIT & Citrate & + & + \\
\hline 8 & CL4 & Colistin & - & - \\
\hline 9 & ESC & Esculin hydrolysis & + & + \\
\hline 10 & FD64 & Nitrofurantoin & - & - \\
\hline 11 & GLU & Glucose & + & + \\
\hline 12 & $\mathrm{H} 2 \mathrm{~S}$ & Hydrogen sulfide & - & - \\
\hline 13 & IND & Indole & - & - \\
\hline 14 & INO & Inositol & + & + \\
\hline 15 & K4 & Kanamycin & - & + \\
\hline 16 & LYS & Lysine & + & + \\
\hline 17 & MAL & Malonate & + & + \\
\hline 18 & MEL & Melibiose & + & + \\
\hline 19 & NIT & Nitrate & + & - \\
\hline 20 & OF/G & $\begin{array}{c}\text { Oxidation- } \\
\text { Fermentation }\end{array}$ & + & + \\
\hline 21 & ONPG & Galactosidase & + & + \\
\hline 22 & ORN & Ornithine & + & + \\
\hline 23 & OXI & Oxidase & - & - \\
\hline 24 & P4 & Penicillin & + & + \\
\hline 25 & RAF & Raffinose & + & + \\
\hline 26 & RHA & Rhamnose & + & + \\
\hline 27 & SOR & Sorbitol & + & + \\
\hline 28 & SUC & Sucrose & + & + \\
\hline 29 & TAR & Tartrate & + & + \\
\hline 30 & TDA & $\begin{array}{l}\text { Tryptophan } \\
\text { Deaminase }\end{array}$ & - & - \\
\hline 31 & TO4 & Tobramycin & - & - \\
\hline 32 & URE & Urea & - & - \\
\hline 33 & VP & Voges-Proskauer & + & - \\
\hline
\end{tabular}

-: negative; +: positive

Table 3: Effect of biofield treatment on multidrug resistant lab isolates of Enterobacter aerogenes to the vital processes occurring in living organisms.

being used now a days to correlate the genetic similarity or mutations between species. The simplicity and wide applicability of RAPD analysis mainly depend on the use of short nucleotide primers, which were unrelated to known DNA sequences of the target organism [33]. DNA polymorphism can be efficiently detected using PCR primers and identify interstrain variations among species in treated samples [34]. The degree of relatedness and genetic mapping can be correlated between similar or different treated sample species [35].

Random amplified polymorphic-DNA fragment patterns of $E$. aerogenes control, and treated samples were generated using five RAPD primers and shown in Figure 1, with 100 base pair (bp) of DNA ladder. The polymorphic bands in control and treated samples are marked by arrows. The RAPD patterns of treated samples showed some unique and dissimilar bands among control and treated samples. DNA polymorphism analyzed by RAPD analysis, total number of bands, common, and unique bands were summarized in Table 4. The level of polymorphism between control and treated samples (A, A1, B, and B1) are summarized in Table 5. The level of polymorphism was found in an average range of 4 to $42 \%$ in treated samples as compared 
Citation: Trivedi MK, Branton A, Trivedi D, Nayak G, Gangwar M, et al. (2015) Characterization of Phenotype and Genotype of Biofield Treated Enterobacter aerogenes. Transl Med 5: 155. doi:10.4172/2161-1025.1000155

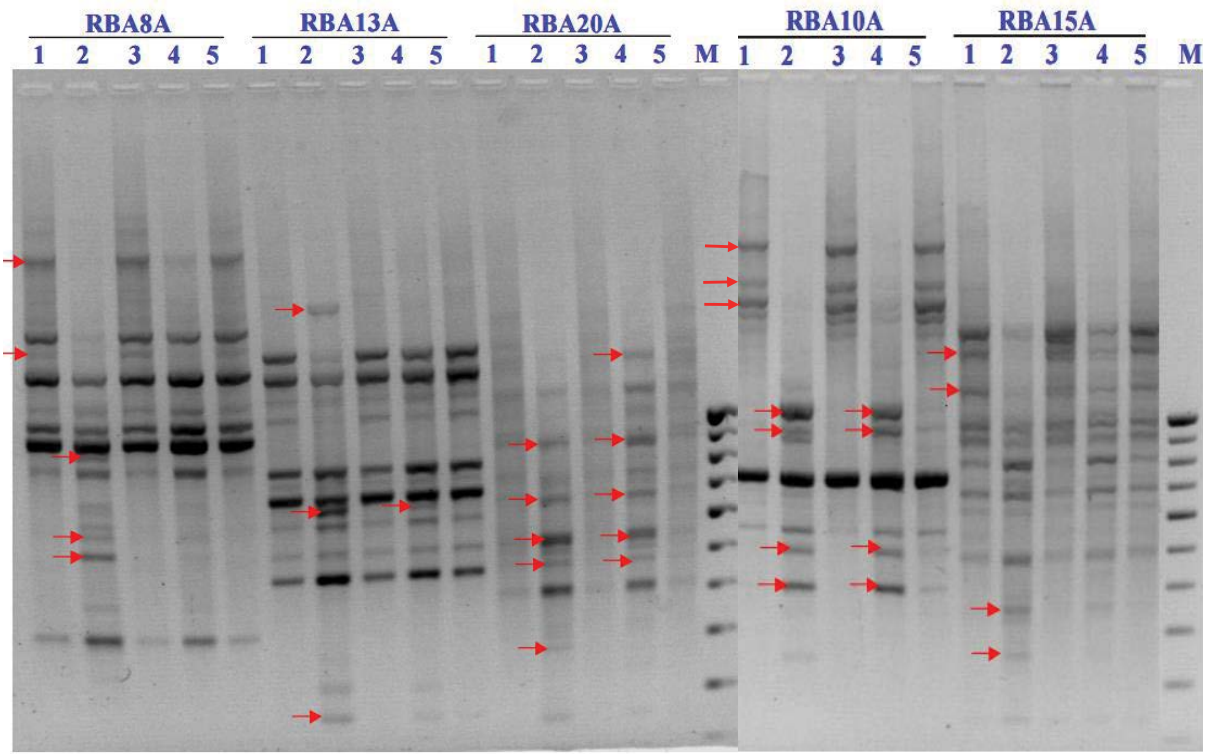

Lane 1 to 5 represents as 1: control, 2: treated A, 3: treated A1, 4: treated B, 5: treated B-1; M: 100 bp DNA Ladder; Polymorphic DNA bands are marked by arrows

Figure 1 Random amplified polymorphic-DNA fragment patterns of Enterobacter aerogenes generated using five RAPD primers, RBA 8A, RBA 13A, RBA 20A, RBA 10A and RBA 15A.

\begin{tabular}{|c|c|c|c|c|c|c|c|c|c|}
\hline \multirow{2}{*}{ S. No. } & \multirow[t]{2}{*}{ Primer } & \multirow{2}{*}{$\begin{array}{c}\text { Nucleotide sequence } \\
\left(5^{\prime}-3^{\prime}\right)\end{array}$} & \multirow{2}{*}{ Bands scored } & \multirow{2}{*}{$\begin{array}{l}\text { Common bands in } \\
\text { control and treated }\end{array}$} & \multicolumn{5}{|c|}{ Unique band } \\
\hline & & & & & Control & TSA & TSA-1 & TSB & TSB-1 \\
\hline 1 & RBA 8A & GTTTCGCTCC & 15 & 7 & - & 1 & - & - & - \\
\hline 2 & RBA 13A & GTGGATCCGA & 14 & 10 & - & 2 & - & - & - \\
\hline 3 & RBA 20A & GCGATCCCCA & 12 & 7 & - & 1 & - & 1 & 1 \\
\hline 4 & RBA 10A & CCGCAGCCAA & 13 & 1 & - & - & - & - & - \\
\hline 5 & RBA 15A & AAGAGCCCGT & 11 & 8 & - & 1 & - & - & - \\
\hline
\end{tabular}

TSA: treated sample A; TSA-1: treated sample A-1; TSB: treated sample B; TSB-1: treated sample B-1.

Table 4: DNA polymorphism analyzed by random amplified polymorphic DNA (RAPD) analysis.

\begin{tabular}{|c|c|c|c|c|c|c|c|c|}
\hline Primer & $C$ and TSA & C and TSA-1 & $C$ and TSB & $C$ and TSB-1 & TSA and TSA-1 & TSB and TSB-1 & TSA and TSB & TSA-1 and TSB-1 \\
\hline RBA 8A & $33 \%$ & $0 \%$ & $0 \%$ & $0 \%$ & $25 \%$ & $0 \%$ & $33 \%$ & $0 \%$ \\
\hline RBA $13 A$ & $30 \%$ & $0 \%$ & $10 \%$ & $0 \%$ & $30 \%$ & $9 \%$ & $20 \%$ & $0 \%$ \\
\hline RBA 20A & $41 \%$ & $0 \%$ & $50 \%$ & $0 \%$ & $45 \%$ & $45 \%$ & $11 \%$ & $0 \%$ \\
\hline RBA $10 A$ & $70 \%$ & $30 \%$ & $70 \%$ & $0 \%$ & $40 \%$ & $44 \%$ & $0 \%$ & $30 \%$ \\
\hline RBA 15A & $40 \%$ & $20 \%$ & $20 \%$ & $20 \%$ & $18 \%$ & $0 \%$ & $20 \%$ & $0 \%$ \\
\hline Average polymorphism & $42 \%$ & $10 \%$ & $30 \%$ & $4 \%$ & $31 \%$ & $19 \%$ & $16 \%$ & $6 \%$ \\
\hline
\end{tabular}

C: control; TSA: treated sample A; TSA-1: treated sample A-1; TSB: treated sample B; TSB-1: treated sample B-1

Table 5: Level of polymorphism between control and treated samples after biofield treatment.

to control, while 6 to $31 \%$ among treated samples of E. aerogenes after the biofield treatment. The highest change (70\%) in DNA sequence was observed in treated groups with RBA 10A primer as compared to the control; however no change was found in treated group (control and $\mathrm{A} 1, \mathrm{~B}$, and $\mathrm{B} 1 ; \mathrm{B}$ and $\mathrm{B} 1, \mathrm{~A} 1$ and $\mathrm{B} 1$ ) with $\mathrm{RBA} 8 \mathrm{~A}$ primer as compared to the control. Likewise, RBA13A and RBA20A also showed no polymorphism between control and treated samples of E. aerogenes after the biofield treatment (Table 5). In the present exploration, difference of polymorphic bands DNA were visualized and scored accordingly. Most of the polymorphic bands shown in the gel image were more than $500 \mathrm{bp}$, while some bands were reported to have around 150 and 250 bp. The primer RBA10A, showed three and four polymorphic bands (marked by arrow) in control and treated (A and B), while RBA20A showed five polymorphic bands in treated samples (A and B) only.

\section{$16 S$ rDNA genotyping}

Molecular PCR assay based on 16S rDNA amplification protocol using standard forward and reverse $16 \mathrm{~S}$ universal primers have been commonly used as a taxonomic "gold standard" in identification and determining the phylogenies of bacterial species [36]. 16S rDNA sequencing was performed in biofield treated E. aerogenes to identify the other closely related species of treated sample. The alignment and comparison of the gene sequences were performed with the sequences stored in Gen Bank database available from NCBI using the algorithm BLASTn program. Based on nucleotides homology and phylogenetic analysis the Microbe (Sample 8A) was closely detected as genus-species to Kluyvera cryocrescens (GenBank Accession Number: AM184245) with $97 \%$ identity, which was nearest homolog genus-species to Enterobacter aerogenes (Accession No. AB244467). The closest sequences of $E$. aerogenes obtained from sequence alignment using NCBI GenBank and ribosomal database project (RDP) was presented 
Citation: Trivedi MK, Branton A, Trivedi D, Nayak G, Gangwar M, et al. (2015) Characterization of Phenotype and Genotype of Biofield Treated Enterobacter aerogenes. Transl Med 5: 155. doi:10.4172/2161-1025.1000155

Page 6 of 7

in Table 6. Distance matrix based on nucleotide sequence homology (Using Kimura-2 Parameter) indicates nucleotide similarity and distance identities between sample ' $8 \mathrm{~A}$ ' and other ten closest homologs microbe of $E$. aerogenes was calculated and shown in Table 7. Phylogenetic tree of the partial 16S rDNA gene sequencing using MEGA 3.1 software by neighbor joining method are presented in Figure 2, ten closely related bacterial species as Operational Taxonomic Units (OTUs) in order to investigate the phylogenetic relationship of E. aerogenes among other ten other bacterial species. There were 1486 base nucleotides of $16 \mathrm{~S}$
rDNA gene sequences were analyzed and multiple alignment were constructed using ClustalW in MEGA 3.1 software [25]. According to the data in Table 7, the lowest value of the genetic distance from $E$. aerogenes was 0.031 base substitutions per site. All pairwise distance analysis was carried out using the p-distance method in MEGA 3.1. The proportion of remarked distance, sometimes also called p-distance and showed as the number of nucleotide distances site. Values in Table 7 were programmed into Figure 2 with optimal bootstrap consensus tree.

\begin{tabular}{|c|c|c|c|}
\hline Alignment View & ID & Alignment results & Sequence description \\
\hline$\square$ & $8 \mathrm{~A}$ & 0.87 & Sample studied \\
\hline$\square$ & AB244467 & 0.99 & Enterobacter aerogenes strain: C1111 \\
\hline$\square$ & AB244456 & 0.98 & Enterobacter aerogenes strain: An19-2 \\
\hline$\square$ & AB244445 & 0.98 & Enterobacter aerogenes strain: An10-1 \\
\hline$\square$ & AJ251468 & 0.98 & Enterobacter aerogenes strain NCTC10006T \\
\hline$\square$ & AB244472 & 0.97 & Enterobacter aerogenes strain: NC4211 \\
\hline$\square$ & AB244302 & 0.97 & Enterobacter aerogenes strain: A13-1 \\
\hline$\square$ & EU304255 & 0.98 & Pantoea agglomerans \\
\hline$\square$ & Y17666 & 0.98 & Klebsiella ornithinolytica strain FSK9555 \\
\hline$\square$ & Y17670 & 0.99 & Klebsiella terrigena strain SW4 \\
\hline$\square$ & AM184245 & 0.97 & Kluyvera cryocrescens strain WAB1904 \\
\hline
\end{tabular}

Table 6: The closest sequences of Enterobacter aerogenes from sequence alignment using NCBI GenBank and ribosomal database project (RDP).

\begin{tabular}{|c|c|c|c|c|c|c|c|c|c|c|c|c|}
\hline \multicolumn{13}{|c|}{ Distance Matrix } \\
\hline AN & & 1 & 2 & 3 & 4 & 5 & 6 & 7 & 8 & 9 & 10 & 11 \\
\hline AB244445 & 1 & - & 0.999 & 1 & 0.987 & 1 & 0.992 & 1 & 0.988 & 0.992 & 0.999 & 0.972 \\
\hline AB244302 & 2 & 0.001 & - & 0.999 & 0.987 & 0.999 & 0.992 & 0.999 & 0.987 & 0.992 & 1 & 0.971 \\
\hline AB244456 & 3 & 0.000 & 0.001 & - & 0.987 & 1 & 0.992 & 1 & 0.988 & 0.992 & 0.999 & 0.972 \\
\hline EU304255 & 4 & 0.013 & 0.013 & 0.013 & - & 0.987 & 0.989 & 0.987 & 0.999 & 0.987 & 0.987 & 0.965 \\
\hline AJ251468 & 5 & 0.000 & 0.001 & 0.000 & 0.013 & - & 0.992 & 1 & 0.988 & 0.992 & 0.999 & 0.972 \\
\hline Y17666 & 6 & 0.008 & 0.009 & 0.008 & 0.011 & 0.008 & - & 0.992 & 0.990 & 0.990 & 0.992 & 0.971 \\
\hline AB244467 & 7 & 0.000 & 0.001 & 0.000 & 0.013 & 0.000 & 0.008 & - & 0.988 & 0.992 & 0.999 & 0.972 \\
\hline Y17670 & 8 & 0.012 & 0.013 & 0.012 & 0.001 & 0.012 & 0.010 & 0.012 & - & 0.987 & 0.987 & 0.966 \\
\hline AM184245 & 9 & 0.008 & 0.009 & 0.008 & 0.013 & 0.008 & 0.010 & 0.008 & 0.013 & - & 0.992 & 0.969 \\
\hline AB244472 & 10 & 0.001 & 0.000 & 0.001 & 0.013 & 0.001 & 0.009 & 0.001 & 0.013 & 0.009 & - & 0.971 \\
\hline $8 \mathrm{~A}$ & 11 & 0.028 & 0.029 & 0.028 & 0.035 & 0.028 & 0.029 & 0.028 & 0.034 & 0.031 & 0.029 & - \\
\hline
\end{tabular}

AN: Accession number

Table 7: Distance matrix based on nucleotide sequence homology (Using Kimura-2 Parameter) indicates nucleotide similarity (above diagonal) and distance (below diagonal) identities between the studied sample ' $8 \mathrm{~A}$ ' and ten closest homologs microbe.

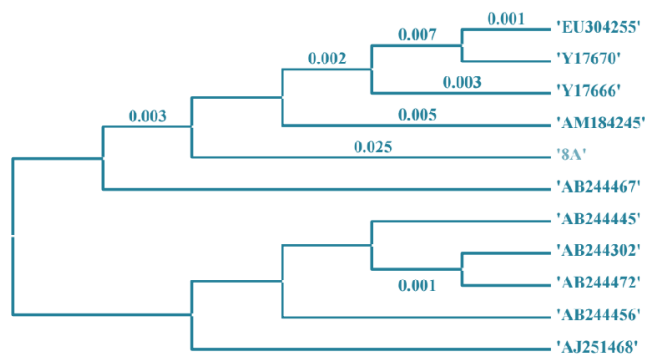

Figure 2 Phylogenetic tree of the partial 16S rDNA gene sequencing using MEGA 3.1 software by Neighbor joining method. Numbers represent GenBank accession number 
Citation: Trivedi MK, Branton A, Trivedi D, Nayak G, Gangwar M, et al. (2015) Characterization of Phenotype and Genotype of Biofield Treated Enterobacter aerogenes. Transl Med 5: 155. doi:10.4172/2161-1025.1000155

Page 7 of 7

In the phylogram, there were eleven OTUs. Based on the phylogenetic tree and $16 \mathrm{~S}$ rDNA sequencing, the nearest homolog genus-species was found to be E. aerogenes.

\section{Conclusion}

Based on these results, it can be concluded that biofield treatment has the significant impact in altering the sensitivity of antimicrobials against E. aerogenes. Mr. Trivedi's biofield energy treatment on E. aerogenes showed improved the sensitivity of resistant chloramphenicol, while decreased MIC value by two folds, in case of chloramphenicol and norfloxacin against $E$. aerogenes as compared to control. Biochemical reactions were also altered followed by change in biotype number after biofield treatment. Using RAPD markers, the sample was characterized and showed 4 to $42 \%$ interspecific polymorphic relationship with $E$. aerogenes after biofield treatment. Molecular method using $16 \mathrm{~S}$ rDNA analysis showed that sample detected as Kluyvera cryocrescens with $97 \%$ identity, which was nearest homolog species to Enterobacter aerogenes. Overall, it seems that Mr. Trivedi's unique biofield treatment might be used as an alternate treatment approach in future than the existing antimicrobial therapy.

\section{Acknowledgement}

This work was supported by Trivedi Science ${ }^{\mathrm{TM}}$, Trivedi Master Wellness ${ }^{\mathrm{TM}}$ and Trivedi Testimonials. Authors acknowledge the generosity and cooperation of all participating members of PD Hinduja National Hospital and MRC, Mumbai, Microbiology Lab for conduction antimicrobial studies. Authors are thankful to Bangalore Genei Private Limited, for conducting RAPD and 16S rDNA sequencing analysis.

\section{References}

1. Arpin C, Coze C, Rogues AM, Gachie JP, Bebear C, et al. (1996) Epidemiological study of an outbreak due to multidrug-resistant Enterobacter aerogenes in a medical intensive care units. J Clin Microbiol 34: 2163-2169.

2. Chow JW, Fine MJ, Shlaes DM, Quinn JP, Hooper DC, et al. (1991) Enterobacter bacteremia: Clinical features and emergence of antibiotic resistance during therapy. Ann Intern Med 115: 585-590.

3. Mallea M, Chevalier J, Bornet C, Eyraud A, Davin-Regli A, et al. (1998) Porin alteration and active efflux: Two in vivo drug resistance strategies used by Enterobacter aerogenes. Microbiology 144: 3003-3009.

4. Stein A, Raoult D (2002) Colistin: An antimicrobial for the $21^{\text {st }}$ century? Clin Infect Dis 35: 901-902.

5. Biswas S, Brunel JM, Dubus JC, Reynaud-Gaubert M, Rolain JM (2012) Colistin: An update on the antibiotic of the 21st century. Expert Rev Anti Infect Ther 10: 917-934.

6. Lucchetti G, de Oliveira RF, Goncalves JP, Ueda SM, Mimica LM, et al. (2013) Effect of spiritist "passe" (Spiritual healing) on growth of bacterial cultures. Complement Ther Med 21: 627-632.

7. Jain S, Mills PJ (2010). Biofield therapies: Helpful or full of hype? A best evidence synthesis. Int J Behav Med 17: 1-16.

8. Movaffaghi Z, Farsi M (2009) Biofield therapies: Biophysical basis and biological regulations. Complement Ther Clin Pract 15: 35-37.

9. Benor DJ (1990) Survey of spiritual healing research. Complement Med Res 4: 9-33.

10. Rein G (1995) The in vitro effect of bioenergy on the conformational states of human DNA in aqueous solution. Acupunct Electrother Res 20: 173-180.

11. Rubik B, Brooks AJ, Schwartz GE (2006) In vitro effect of Reiki treatment on bacterial cultures: Role of experimental context and practitioner wellbeing. $J$ Altern Complement Med 12: 7-13.

12. Trivedi MK, Tallapragada RR (2008) A transcendental to changing metal powder characteristics. Met Powder Rep 22-28,31.
13. Dabhade VV, Tallapragada RR, Trivedi MK (2009) Effect of external energy on atomic, crystalline and powder characteristics of antimony and bismuth powders. Bull Mater Sci 32: 471-479.

14. Trivedi MK, Nayak G, Patil S, Tallapragada RM, Latiyal O (2015) Studies of the atomic and crystalline characteristics of ceramic oxide nano powders after bio field treatment. Ind Eng Manage 4: 161.

15. Shinde V, Sances F, Patil S, Spence A (2012) Impact of biofield treatment on growth and yield of lettuce and tomato. Aust J Basic Appl Sci 6: 100-105.

16. Sances F, Flora E, Patil S, Spence A, Shinde V (2013) Impact of biofield treatment on ginseng and organic blueberry yield. Agrivita J Agric Sci 35: 22-29.

17. Lenssen AW (2013) Biofield and fungicide seed treatment influences on soybean productivity, seed quality and weed community. Agricultural Journal 8: 138-143.

18. Nayak G, Altekar N (2015) Effect of biofield treatment on plant growth and adaptation. J Environ Health Sci 1: 1-9.

19. Trivedi MK, Patil S, Shettigar H, Bairwa K, Jana S (2015) Phenotypic and biotypic characterization of Klebsiella oxytoca: An impact of biofield treatment. J Microb Biochem Technol 7: 203-206.

20. Trivedi MK, Patil S, Shettigar H, Gangwar M, Jana S (2015) An effect of biofield treatment on Multidrug-resistant Burkholderia cepacia: A multihost pathogen. $J$ Trop Dis 3: 167.

21. Trivedi MK, Patil S, Shettigar H, Gangwar M, Jana S (2015) Antimicrobial sensitivity pattern of $P$ seudomonas fluorescens after biofield treatment. J Infect Dis Ther 3: 222.

22. Fader RC, Weaver E, Fossett R, Toyras M, Vanderlaan J, et al. (2013) Multilaboratory study of the biomic automated well-reading instrument versus MicroScan WalkAway for reading MicroScan antimicrobial susceptibility and identification panels. J Clin Microbiol 51: 1548-1554.

23. Welsh J, McClelland M (1990) Fingerprinting genomes using PCR with arbitrary primers. Nucleic Acids Res 18: 7213-7218.

24. Alm EW, Oerther DB, Larsen N, Sthal DA, Raskin L (1996) The oligonucleotide probe database. Appl Environ Microbiol 62: 3557-3559.

25. Kumar S, Tamura K, Nei M (2004) MEGA3: Integrated software for molecular evolutionary genetics analysis and sequence alignment. Brief Bioinform 5: 150163.

26. Clarke TC, Black LI, Stussman BJ, Barnes PM, Nahin RL (2015) Trends in the use of complementary health approaches among adults: Unites States, 20022012, National Center for Health Statistics.

27. Navarro F, Miró E, Mirelis B (2010) Interpretive reading of enterobacteria antibiograms. Enferm Infecc Microbiol Clin 28: 638-648.

28. Ghisalberti D, Masi M, Pages JM, Chevalier J (2005) Chloramphenicol and expression of multidrug efflux pump in Enterobacter aerogenes. Biochem Biophys Res Commun 328: 1113-1138.

29. Choi SH, Lee JE, Park SJ, Choi SH, Lee SO, et al. (2008) Emergence of antibiotic resistance during therapy for infections caused by Enterobacteriaceae producing $A m p C$ beta-lactamase: Implications for antibiotic use. Antimicrob Agents Chemother 52: 995-1000.

30. Norrby SR (1995) Carbapenems. Med Clinics North America 79: 745-59.

31. Koneman EW (2006) Koneman's Color Atlas and Textbook of Diagnostic Microbiology. (6thedn), Lippincott Williams \& Wilkins.

32. MacFaddin JF (1980) Biochemical tests for identification of medical bacteria (2ndedn), Williams and Wilkins, Baltimore.

33. Williams JGK, Kubelik AR, Livak KJ, Rafalski JA, Tingey SV (1990) DNA polymorphisms amplified by arbitrary primers are useful as genetic markers. Nucleic Acids Res 18: 6531-6535.

34. Bingen E, Boissinot C, Desjardins P, Cave H, Brahimi N, et al. (1993) Arbitrarily primed polymerase chain reaction provides rapid differentiation of Proteus mirabilis isolates from a pediatric hospital. J Clin Microbiol 31: 1055-1059.

35. Williams JG, Hanafey MK, Rafalski JA, Tingey SV (1993) Genetic analysis using random amplified polymorphic DNA markers. Methods Enzymol 218: 704-744.

36. Woese CR (1987) Bacterial evolution. Microbiol Rev 51: 221-271 